\title{
The Wall Structure of Schizosaccharomyces pombe
}

\author{
By D. A. BUSH, M. HORISBERGER, I. HORMAN AND P. WURSCH \\ Research and Development Department, \\ Nestlé Products Technical Assistance Ltd, Lausanne, Switzerland
}

(Received 8 August I973; revised I I October 1973)

\begin{abstract}
SUMMARY
The wall structure of the fission yeast Schizosaccharomyces pombe, examined by enzymic techniques, consists of a galactomannan, an $\alpha$-glucan and $\beta$-glucan. The structures of the $\alpha$-glucan and galactomannan were investigated by methylation. The wall structure is discussed in relation to the taxonomic position of the genus Schizosaccharomyces.
\end{abstract}

\section{INTRODUCTION}

Although the wall composition of fungi and their major taxonomic groupings (BartnickiGarcia, I968) are related, yeasts are an exception. Detailed investigations of the wall structure of micro-organisms considered intermediate between yeasts and fungi may give some indications of the nature of the relationship of yeasts to fungi. The so-called fission yeasts of the genus Schizosaccharomyces are taxonomically nearer to the ascomycetes than are budding yeasts and at least one member of this genus, $S$. versatilis, forms true mycelium to a certain extent (Phaff, Miller \& Mrak, I966). The walls of $S$. pombe, $S$. octosporus and $S$. versatilis do not have the $\beta$-glucan, $\alpha$-mannan structure found in many other yeasts; mannan and chitin are absent and one-third of the glucan is $\alpha$-(I $\rightarrow 3)$-linked (Bacon, Jones, Farmer \& Webley, I968). These workers also suggested that the intimate association between the $\alpha$ - and $\beta$-glucans in the walls of $S$. pombe make them resistant to attack by $\beta$-(I $\rightarrow 3)$ and $\beta$-(I $\rightarrow 6$ ) glucanases as found by Tanaka \& Phaff (I966). Manners \& Masson (1969), using acetic acid extraction, identified separate $\beta$ - $(\mathrm{I} \rightarrow 3)$ and $\beta$ - $(\mathrm{I} \rightarrow 6)$ glucans from the walls of Saccharomyces cerevisiae and suggested that the walls of $S$. pombe could be similar.

Galactomannans have been isolated from the walls of four species of Schizosaccharomyces by extraction with alkali followed by precipitation with Fehling's solution (Gorin \& Spencer, I968), but Kreger (I954), found no precipitate at all with Fehling's solution. When walls of S. pombe were fractionated in alkali (Deshusses, Berthoud \& Posternak, 1969) $59 \%$ of the wall was polysaccharide containing glucan $(85 \%)$, mannan $(4 \%)$ and galactan $(0.9 \%)$. Poole \& Lloyd (1973), however, besides finding glucose $(37 \%)$ and mannose (10\%) in hydrolysates of the wall of $S$. pombe $972 \mathrm{~h}^{-}$also identified glucosamine $(8 \%)$, which contrasts with most of the previous work on this yeast.

A structural analysis of the walls of Schizosaccharomyces pombe was carried out with the methods previously used for Saccharomyces cerevisiae (Bauer, Bush \& Horisberger, 1972) in the hope of elucidating some of the more controversial points mentioned above. 


\section{METHODS}

Preparation of walls. Schizosaccaromyces pombe Lindner CBS35 I (Fig. 1), from the Centraalbureau voor Schimmelcultures, Baarn, Holland, was shaken for $24 \mathrm{~h}$ at $25^{\circ} \mathrm{C}$ in $500 \mathrm{ml}$ flasks containing $150 \mathrm{ml}$ of a glucose $(2 \%)$, yeast extract $(0.5 \%)$, salts medium. The yeast was harvested by centrifuging; the walls (Fig. 2) were prepared by the method of Mill (1966) and were judged clean by microscopical examination (Horisberger, Bauer \& Bush, 1971).

Analysis of walls and degradation products. Total sugar was measured by the phenolsulphuric acid method (Dubois et al. 1956) and the sugars in the wall were identified - after dissolving in $72 \% \mathrm{H}_{2} \mathrm{SO}_{4}$ at $0{ }^{\circ} \mathrm{C}$ and hydrolysing in $8 \% \mathrm{H}_{2} \mathrm{SO}_{4}$ at $100{ }^{\circ} \mathrm{C}$ for $4 \mathrm{~h}$ (Bouveng \& Lindberg, 1965) - as their alditol acetates as previously described (Bush \& Horisberger, 1973). Glucosamine was measured after hyrolysis in $6 \mathrm{M}-\mathrm{HCl}$ for $\mathrm{I} 5 \mathrm{~h}$ at $100{ }^{\circ} \mathrm{C}$ by the method of Brownlee \& Wheat (I966). Reducing groups were determined by the Nelson Somogyi method (Nelson, I944) and D-glucose by the D-glucose oxidase method (Huggett \& Nixon, I957). Disaccharides were identified as their alditol acetates by gas-liquid chromatography using a copper column $(100 \times 0.6 \mathrm{~cm})$ with $40 \mathrm{ml} \mathrm{N}_{2} / \mathrm{min}$ as carrier gas and a temperature gradient of $4{ }^{\circ} \mathrm{C} / \mathrm{min}$ from 200 to $300{ }^{\circ} \mathrm{C}$. The column was packed with $3 \%$ OV 17 on Chromosorb W (Hewlett Packard, 433 Fair Oaks Avenue, Pasadena, California, U.S.A.).

Polysaccharides were tested for homogeneity by colouring with a dichloro-s-triazinyl dye (Blau GH 2769; Ciba-Geigy, Basle, Switzerland) followed by electrophoresis on cellulose acetate (Dudman \& Bishop, I 968). Polysaccharides were then methylated by the procedure of Hakomori (1964) as described by Sandford \& Conrad (I966) and the methylated derivatives hydrolysed by the formic acid-sulphuric acid method (Bouveng \& Lindberg, 1965). The resulting methyl sugars were identified and measured as their alditol acetates by gasliquid chromatography using column A (OV-225) and column B (ECNSS-M) (Hewlett Packard) as described by Lönngren \& Pilotti (197I). The identity of all methyl sugars was confirmed by combined gas-liquid chromatography and mass spectrometry performed on a Pye gas chromatograph coupled to an AEI MS 20 mass spectrometer, using column A.

Walls $(20 \mathrm{mg})$ were also degraded using purified exo- $\beta$ - $(\mathrm{I} \rightarrow 3)$ glucanase (200 units) (Huotari, Nelson, Smith \& Kirkwood, I968) from Basidiomycete QM806 (Reese \& Mandels, 1959). The degradation products were assayed as described by Bauer et al. (1972).

\section{RESULTS}

\section{Carbohydrate content of yeast walls}

Walls contained $97 \%$ carbohydrate, as measured with the phenol-sulphuric acid method. When walls were hydrolysed before sugar determination, the value dropped to $89 \%$, indicating that hydrolysis had caused some degradation of the sugars. Glucose $(91 \cdot 3 \%)$, mannose $(5.6 \%)$ and galactose $(3.2 \%)$ were identified in the hydrolysed wall preparations but no glucosamine could be detected.

\section{$\beta-(\mathrm{I} \rightarrow 3)$ glucanase digestion of yeast walls}

The total sugar in the supernatant solution after degrading walls with glucanase represented $69 \%$ of the wall and $42 \%$ of the total reducing sugars and glucose. The total sugar in the residue of the glucanase digest was $28 \%$ of the wall. These analyses indicated that the wall contained $42 \% \beta$-(I $\rightarrow 3)$-linked glucose residues and that $28 \%$ of the wall was solubi- 

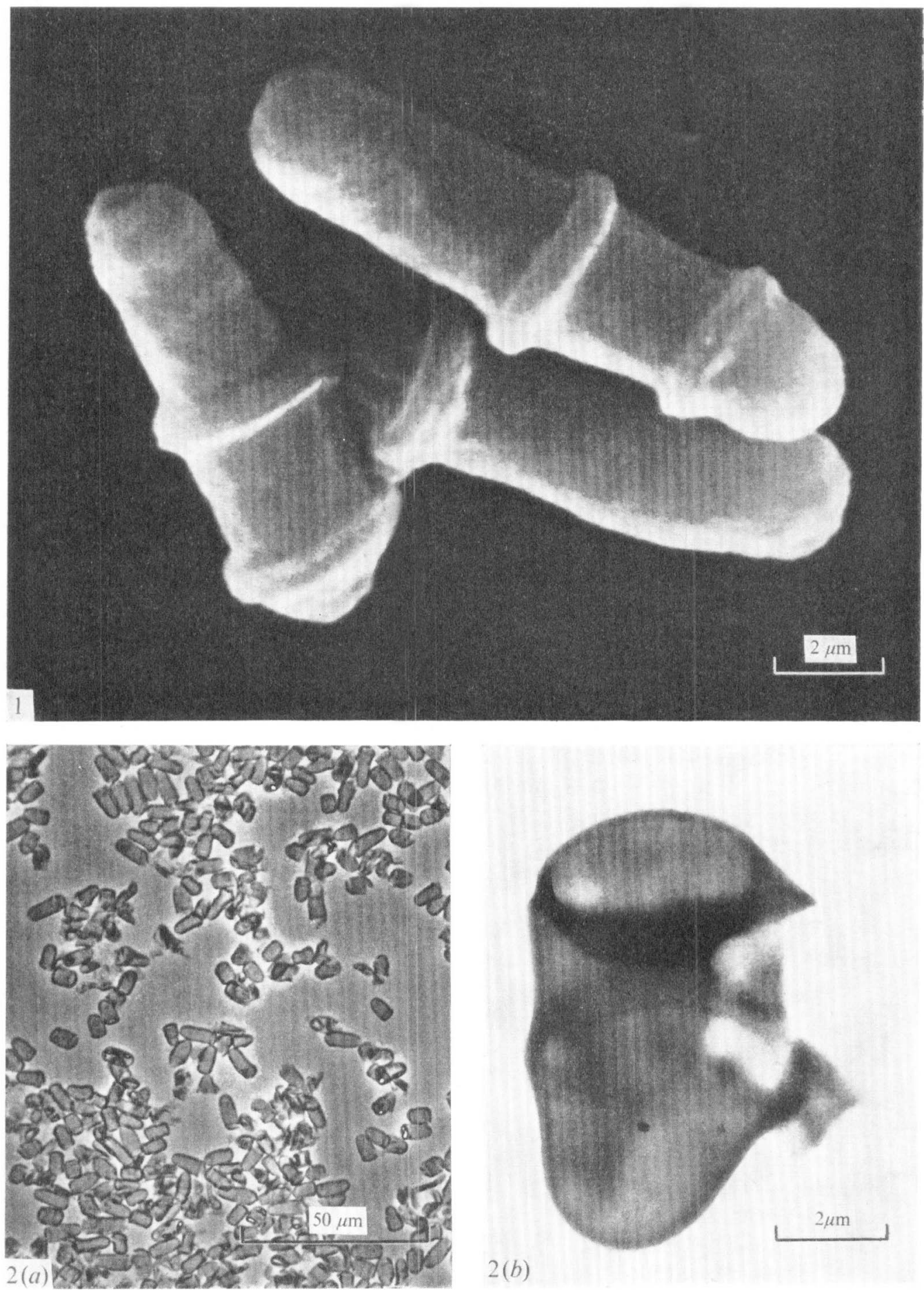

2 (b)

Fig. 1. Electron micrograph of Schizosacchoromyces pombe.

Fig. 2(a) Phase-contrast micrograph of the wall preparation of Schizosaccharomyces pombe. (b) Electron micrograph of an isolated wall of Schizosaccharomyces pombe. 
lized by the $\beta$ - $(\mathrm{I} \rightarrow 3)$ glucanase without degradation. The supernatant and the residue were dialysed against distilled water, after which they were hydrolysed and the resulting sugars converted to their alditol acetates and measured by gas-liquid chromatography. The residue contained glucose $(89 \%)$, mannose $(8 \%)$ and galactose $(3 \%)$, and the dialysed supernatant contained mannose $(34 \%)$, galactose $(20 \%)$ and glucose $(46 \%)$. The dialysate contained glucose $(96 \%)$, gentiobiose $(3.5 \%)$ and laminaribiose $(0.5 \%)$.

\section{Methylation studies on walls and glucanase-digested walls}

To obtain sufficient material for methylation studies, walls $(200 \mathrm{mg})$ were digested as before with glucanase (2000 units). The residue (R) was washed, dialysed and freeze dried, and consisted of glucose $(93 \%)$, mannose $(4.2 \%)$ and galactose $(2.5 \%)$, corresponding with previous results. The supernatant $\left(\mathrm{S}_{1}\right)$ was dialysed, treated with trichloracetic acid (I0\%) at ${ }^{\circ} \mathrm{C}$ to remove the enzyme, and Fehling's solution at $\mathrm{pH}$ io was added. The precipitate was removed by centrifuging, washed in $0 \cdot 1 \mathrm{M}-\mathrm{HCl}$, dialysed and freeze-dried $\left(\mathrm{S}_{2}\right)$. This material contained mannose $(6 \mathrm{I} \%)$, galactose $(30 \%)$, and glucose $(9 \%)$. Repeated precipitations with Fehling's solution of a part of $\mathrm{S}_{2}$ reduced the glucose content to less than $2 \%$, indicating that most of the glucose was not part of the polysaccharide. This preparation now ran as a single band when subjected to cellulose acetate electrophoresis (Dudman \& Bishop, 1968), but as the amount of material was much decreased, the original preparation of $S_{2}$ had to be used in methylation studies.

The residue $(\mathrm{R}, 10 \mathrm{mg})$ and the supernatant $\left(\mathrm{S}_{2}, 5 \mathrm{mg}\right)$ were methylated twice and a sample of the wall preparation $(20 \mathrm{mg})$ was methylated three times. A variety of methyl sugars was obtained after hydrolysis of the methylated fractions (Table I). From these results, the wall of Schizosaccharomyces pombe appears to consist of at least three major polysaccharides: $\beta-(\mathrm{I} \rightarrow 3)$ glucan, which is degraded by the $\beta-(\mathrm{I} \rightarrow 3)$ glucanase; a residue consisting mainly of $(\mathrm{I} \rightarrow 3)$ linkages which since it was not degraded by the $\beta$-glucanase is probably $\alpha$-linked; and galactomannan. The presence of a separate $\beta$-(I $\rightarrow 6)$-linked glucan cannot be discounted.

Galactomannan. Methylation and hydrolysis of the Fehling's precipitate $\left(\mathrm{S}_{2}\right)$ gave rise to methyl mannitols $(55 \%)$, methyl galactitols $(32 \%)$ and methyl glucitols $(8 \%)$. The latter, mainly 2,4,6-tri- $O$-methyl glucitol, arose almost certainly from contamination by one of the $(\mathrm{I} \rightarrow 3$ )-linked glucans, so that the methylated galactomannan gave rise to $2,3,4,6$-tetra- $O$ methyl galactitol, 2,3,4-tri- $O$-methyl mannitol and 3,4-di- $O$-methyl mannitol in almost equimolar proportions. Methylation of the galactomannan from Schizosaccharomyces octosporus (Gorin, Spencer \& Magus, 1969) gave rise to 2,3,4,6-tetra- $O$-methyl galactose, 2,3,4,6-tetra- $O$-methyl mannose, 2,4,6-tri- $O$-methyl galactose, 2,3,4-tri- $O$-methyl mannose and 3,4 -di- $O$-methyl mannose in the ratio $8 \cdot 6: 1 \cdot 4: 7 \cdot 3: 9 \cdot 8$. The di- $O$-methyl mannose was not measured. The specific rotation of this galactomannan was $+110^{\circ}$ as compared with our value of $+94^{\circ}$, and on partial hydrolysis it gave a mannan with $\alpha-(I \rightarrow 6)$-Dmannopyranose units, suggesting that this formed the backbone of the molecule. The main differences between the galactomannans of $S$. pombe and $S$. octosporus are the presence of mannose units linked through positions I, 4 and 6 in the former and the presence of nonreducing terminal mannose units in the latter. The amount of non-terminal galactose units is higher in $S$. octosporus than in $S$. pombe, but these were not present in any other yeast galactomannans examined by Gorin et al. (1969).

$\alpha$-Glucan. Methylation and hydrolysis of the residue (R) gave (\%):2,4,6-tri- $O$-methyl glucitol (89) and 2,3,6-tri- $O$-methyl glucitol (7), together with small amounts of 2,3,4,6tetra- $O$-methyl glucitol and galactitol (I 4 and $\mathrm{I} \cdot 6$, respectively), 2,4-di- $O$-methyl glucitol 
Table I. Hydrolysis products of methylated walls $(W)$, residue $(R)$ and Fehling's precipitate $\left(S_{2}\right)$

Cleavage products

2,3,4,6-Tetra- $O$-methyl glucitol

2,3,4,6-Tetra- $O$-methyl galacitol

2,4,6-Tri-O-methyl glucitol

2,4,6-Tri- $O$-methyl galacitol

2,3,4-Tri- $O$-methyl

mannitol

2,3,6-Tri-O-methyl

glucitol

4,6-Di- $O$-methyl glucitol

2,4-Di- $O$-methyl glucitol

3,4-Di- $O$-methyl mannitol

2,3-Di-O-methyl mannitol

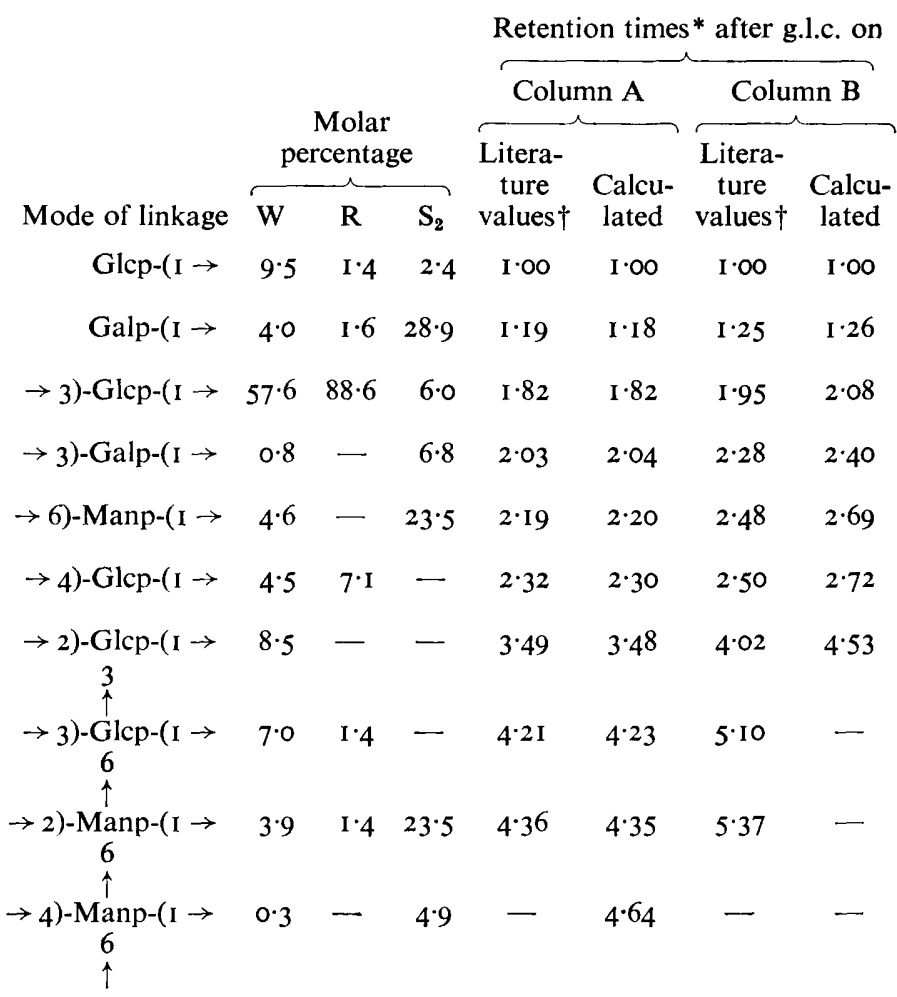

Retention times* after g.l.c. on

$\overbrace{\begin{array}{c}\text { Litera- } \\ \text { ture } \text { Calcu- }\end{array}}^{\text {Column A }} \overbrace{\begin{array}{c}\text { Litera- } \\ \text { ture Calcu- }\end{array} \text { Column B }}^{\text {Calced }}$

ed

$\cdot 26$

$\cdot 08$

40

69

$2 \cdot 72$

$4 \cdot 53$

* Relative to I.5-di- $O$-acetyl-2,3,4,6-tetra- $O$-methyl-D-glucitol.

$\dagger$ Lönngren \& Pilotti (1971).

(I·4) and 3,4-di-O-methyl mannitol (I-4). Methyl mannose and galactose probably both originated from the galactomannan; thus the glucan would appear to be a straight-chain molecule linked $(\mathrm{I} \rightarrow 3)$. Whether the $(\mathrm{I} \rightarrow 4)$ linkages form part of the same molecule is uncertain, but this could be confirmed using specific $\alpha$-glucanases. The small amounts of tetra- and di- $O$-methyl glucitols may indicate a low percentage of branches, but they are more likely to originate from the $\beta$-glucan, which also gives rise to these methyl sugars. As this $(\mathrm{I} \rightarrow 3)$ glucan was not degraded by the $\beta$ - $(\mathrm{I} \rightarrow 3)$ glucanase, it was assumed to be $\alpha$-linked. This was confirmed by the infrared spectrum, which corresponds with that found by Bacon et al. (I968) and the specific rotation $[\alpha]_{\mathrm{D}}^{25}+230^{\circ}($ c. 0.47 in $\mathrm{NaOH})$, which is typical of an $\alpha-(\mathrm{I} \rightarrow 3)$ glucan (Horisberger, Lewis \& Smith, I972).

$\beta$-Glucan. Degradation of yeast walls by the purified exo- $\beta$ - $(\mathrm{I} \rightarrow 3)$ glucanase indicated that there were $42 \% \beta$ - $(\mathrm{I} \rightarrow 3)$ linkages in the wall. A satisfactory separation of the $\beta$-glucan from the other fractions by alkali treatment was not achieved and its structure was therefore determined by methylating the entire walls and the analyses compared with the results of methylating the $\alpha$-glucan and galactomannan.

The residue of the glucanase digest (R) made up $28 \%$ of the wall. Thus of the $58 \%$ 2,4,6-tri- $O$-methyl glucitol found on methylation of the whole wall, about $25 \%$ is accounted for by the $\alpha$-glucan, leaving $33 \%$ from $\beta$-linked glucan. The $2,3,4,6$-tetra- $O$-methyl glucitol 
and 2,4-di-O-methyl glucitol were found only in trace amounts in the galactomannan and $\alpha$-glucan and therefore originated mainly, if not totally, from the $\beta$-glucan(s). The 4,6-di- $O$ methyl glucitol, which was not present in either the methylated $\alpha$-glucan or galactomannan, almost certainly originates from incompletely methylated $(\mathrm{I} \rightarrow 3)$-linked residues which are sometimes found with the methylation of such polysaccharides (Horisberger, I966). If this is so, then the methylation results indicate $45 \% \beta-(\mathrm{I} \rightarrow 3)$ linkages in the wall, but if not, then these linkages only make up $37 \%$ of the wall. Enzyme degradation indicated a figure of $42 \% \beta$ - $(\mathrm{I} \rightarrow 3)$ linkages, so that the two methods are in good agreement. The presence of $\beta$-(I $\rightarrow 4$ ) linkages cannot be discounted as more 2,3,6-tri- $O$-methyl glucitol was found in the wall than could be explained by the $\alpha$-glucan.

2,3,4-Tri- $O$-methyl glucitol has relative retention times of 2.22 on column A and 2.49 on column B (Lönngren \& Pilotti, I97I) and thus cannot be distinguished from 2,3,4-tri- $O$ methyl mannitol (relative retention times 2.19 and 2.48 respectively). Thus, in the methylated walls, there is probably some 2,3,4-tri- $O$-methyl glucitol originating from $(\mathrm{I} \rightarrow 6)$ linkages; this is supported by the walls containing $5.6 \%$ mannose but upon methylation having $8.8 \%$ methyl mannitols. If this is the case, then it supports the findings of Manners \& Masson (1969), who found strong evidence for the presence of a distinct $\beta-(1-6)$ glucan in the walls of Schizosaccharomyces pombe.

\section{DISCUSSION}

The wall structure of Schizosaccharomyces pombe is made up of $\beta$-glucan ( 46 to $54 \%$ ), which may consist of two separate polysaccharides: a glucan with mainly $\beta-(\mathrm{I} \rightarrow 6)$ linkages and a glucan with mainly $\beta$ - $(\mathrm{I} \rightarrow 3)$ linkages. The presence of some $(\mathrm{I} \rightarrow 4)$ linkages in the $\beta$-glucan cannot be discounted. The $x$-glucan $(28 \%)$ is most probably a straight-chain polysaccharide, linked mainly $\alpha-(\mathrm{I} \rightarrow 3)$, but again there is evidence that $(\mathrm{I} \rightarrow 4)$ linkages $(7 \%)$ are present in this molecule. The galactomannan ( 9 to $14 \%$ ) appears to consist of a $(\mathrm{I} \rightarrow 6)$-linked mannose backbone with $(\mathrm{I} \rightarrow 2)$-linked mannose side-chains having nonreducing terminal galactose units. A small amount of non-terminal galactose was found in this galactomannan.

Deshusses et al. (1969) and Poole \& Lloyd (1973) obtained walls containing 57 to $60 \%$ carbohydrate, though in neither case was this measured directly. Our figure of $97 \%$ is more typical of the walls of yeasts and fungi (Bartnicki-Garcia, 1968), but may be somewhat high due to loss of lipid in the ether during the preparation (Mill, 1966).

The detection of a galactomannan as a Fehling's precipitate in the walls contrasts with the results of Kreger (I954), Deshusses et al. (1969) and Poole \& Lloyd (1973). However, Spencer \& Gorin (I973) pointed out that galactomannans may take as long as 2 to 3 months at $4{ }^{\circ} \mathrm{C}$ to precipitate with Fehling's solution and this could account for the previous failures, although Deshusses et al. (1969) did find only a trace of galactose in the walls of $S$. pombe and Poole \& Lloyd (1973) found none. Our results support those of Gorin \& Spencer (1968) and Gorin et al. (1969), who identified galactomannans in several species of Schizosaccharomyces and analysed the structure of that from $S$. octosporus.

The solution of an $\alpha-(\rightarrow 3)$ glucan from the walls of Schizosaccharomyces pombe supports the work of Kreger (1954) and Bacon et al. (1968) and may explain the resistance of $S$. pombe walls to $\beta$ - $(\mathrm{I} \rightarrow 3)$ glucanase found by Tanaka \& Phaff (I966), though the exo- $\beta-$ $(\mathrm{I} \rightarrow 3)$ glucanase of Basidiomycete QM806 was capable of degrading the $\beta-(\mathrm{I} \rightarrow 3)$ glucan. Whether the $\beta$-(I $\rightarrow 3)$ - and $\beta$ - $(\mathrm{I} \rightarrow 6)$-linkages arise from one or more polysaccharides is not yet clear. As the amount of gentiobiose found in the enzyme digest was small compared 
with the amount of 2,4-di- $O$-methyl glucitol found on methylation and hydrolysis of the walls, a part of this di- $O$-methyl sugar could have arisen from a mainly $\beta$ - $(I \rightarrow 6)$-linked glucan which would not have been degraded by the $\beta-(\mathrm{I} \rightarrow 3)$ glucanase. This point is being further examined.

We found no glucosamine in hydrolysates of the wall of Schizosaccharomyces pombe, suggesting chitin to be absent. The absence of chitin in the walls of $S$. octosporus was demonstrated by Roelofsen \& Hoette (I95I) and in S. octosporus, S. pombe and S. versatilis by Kreger (1954), which makes it surprising that glucosamine should be identified in wall hydrolysates by Poole \& Lloyd (I973).

The wall structure of Schizosaccharomyces pombe differs in several important respects from that of budding ascomycetous yeasts such as Saccharomyces cerevisiae. For example, the presence of $x$-glucan could denote a close relationship to mycelial Ascomycetes, many of which contain this polymer in their walls (Bartnicki-Garcia, I968). As mannan and chitin play a part in the budding process of $S$. cerevisiae (Bush \& Horisberger, 1973; Cabib \& Bowers, 1971), the absence of mannan and the presence of galactomannan in $S$. pombe may indicate their involvement in the fission process. These hypotheses are speculative at present, but detailed studies of the structure of the walls of related organisms, especially the mycelial and yeast forms of Schizosaccharomyces versatilis, may help to elucidate them.

The authors thank Dr E. T. Reese, U.S. Army Natick Laboratories, Natick, Massachusetts, U.S.A., for his gift of a culture of Basidiomycete QM806 and Miss Eliane Simon for valuable technical assistance.

\section{REFERENCES}

Bacon, J. S. D., Jones, D., Farmer, V. C. \& Webley, D. M. (I968). The occurrence of $\alpha$-(I $\rightarrow 3$ ) glucan in Cryptococcus, Schizosaccharomyces and Polyporus species, and its hydrolysis by a Streptomyces culture filtrate lysing cell walls of Cryptococcus. Biochimica et biophysica acta 158, 313-315.

BARTNICKI-GARCIA, S. (1968). Cell wall chemistry, morphogenesis and taxonomy of fungi. Annual Review of Microbiology 22, 87-108.

BAUER, H., Bish, D. A. \& HorisBerger, M. (1972). Use of the exo- $\beta$-( I $\rightarrow 3)$ glucanase from Basidiomycete QM806 in studies on yeast. Experientia 28, I I-13.

BouvenG, H. O. \& LindBerG, B. (1965). Hydrolysis of methylated polysaccharides. Methods in Carbohydrate Chemistry 5. 296-298.

Brownlee, S. T. \& WheAt, R. W. (1966). On the determination of galactosamine-uronic acid. Analytical Biochemistry 14, 414-420.

Bush, D. A. \& Horisberger, M. (1973). Mannan of yeast bud scars. A comparison of the structure of bud scar mannan with that of the cell wall of Saccharomyces cerevisiae. Journal of Biological Chemistry 248, $1318-1320$.

CABIB, E. \& Bowers, B. (197I). Chitin and yeast budding. Localization of chitin in yeast bud scars. Journal of Biological Chemistry 246, I52-159.

Deshusses, J., Berthoud, S. \& Posternak, T. (1969). Recherches biochimiques sur Schizosaccharomyces pombe en fonction des conditions de culture et de l'action d'inhibiteurs. II. Composition des parois cellulaires. Biochimica et biophysica acta $\mathbf{1 7 6}, 803-8 \mathrm{I} 2$.

Dubois, M.. Gilles, K. A., Hamilton, J. K., Rebers, P. A. \& Smith, F. (1956). Colorimetric method for determination of sugars and related substances. Analytical Chemistry 28, 350-356.

Dudman, W. F. \& Bishop, C. T. (1968). Electrophoresis of dyed polysaccharides on cellulose acetate. Canadian Journal of Chemistry 46, 3079-3084.

Gorin, P. A. J. \& SPENCER, J. F. T. (I968). Galactomannans of Trichosporon fermentans and other yeasts, proton magnetic resonance and chemical studies. Canadian Journal of Chemistry 46, 2299-2304.

Gorin, P. A. J., SPENCER, J. F. T. \& MAGUS, R. J. (1969). Comparison of proton magnetic resonance spectra of cell-wall mannans and galactomannans of selected yeasts with their chemical structures. Canadian Journal of Chemistry 47, 3569-3576. 
HАкомоRI, S. (1964). A rapid permethylation of glycolipid, and polysaccharide catalyzed by methylsulfinyl carbanion in dimethyl sulfoxide. Journal of Biochemistry 55, 205-208.

Horisberger, M. (1966). Study of pseudonigeran. Ph.D. Thesis, University of Minnesota, Minnesota, U.S.A.

Horisberger, M., BAUER, H. \& BUSH, D. A. (I971). Mercury labelled concanavalin A as a marker in electron microscopy-localization of mannan in yeast cell walls. Federation of European Biochemical Societies Letters 18, 3II-3I4.

Horisberger, M., Lewis, B. A. \& SMith, F. (1972). Structure of a (I $\rightarrow 3$ )- $\alpha$-D-glucan (pseudonigeran) of Aspergillus niger NNRL 326 cell wall. Carbohydrate Research 23, $183-188$.

Huggett, A. St G. \& Nixon, D. A. (I957). Enzymic determination of blood glucose. Biochemical Journal 66, I 2 P.

Huotari, F. I., Nelson, T. E., Smith, F. \& Kirkwood, S. (1968). Purification of an exo- $\beta$-D-(I $\rightarrow$ 3)glucanase from Basidiomycete species QM 806. Journal of Biological Chemistry 243, 952-956.

KREGER, D. R. (1954). Observations on cell walls of yeasts and some other fungi by X-ray diffraction and solubility tests. Biochimica et biophysica acta $\mathbf{2 3}, \mathrm{I}-9$.

LönNGREN, J. \& PILOTTI, Ä. (1971). Gas-liquid chromatography of partially methylated alditols as their acetates. II. Acta chemica scandinavica 25, I I 44-I I45.

MANners, D. J. \& MAsson, A. J. (1969). The structures of two glucans from yeast-cell walls, Federation of European Biochemical Societies Letters 4, I22-I 24.

MiLl, P. J. (I966). Phosphomannans and other components of flocculent and non-flocculent walls of Saccharomyces cerevisiae. Journal of General Microbiology 44, 329-34I.

Nelson, N. (1944). A photometric adaptation of the Somogyi method for the determination of glucose. Journal of Biological Chemistry 153, 375-380.

Phaff, H. J., Miller, M. W. \& Mrak, E. M. (1966). In The Life of Yeasts, p. 15. Cambridge, Massachusetts: Harvard University Press.

Poole, R. K. \& LlOYD, D. (1973). Effect of 2-deoxy-D-glucose on growth and cell walls of Schizosaccharomyces pombe $972 \mathrm{~h}$. Archive für Mikrobiologie 88, 257-272.

Reese, E. T. \& MANDELS, M. (1959). $\beta$-D-I,3 glucanases in fungi. Canadian Journal of Microbiology 5, 173185 .

Roelofsen, P. A. \& Hoette, I. (I95I). Chitin in the cell wall of yeasts. Antonie van Leeuwenhoek 17, 297-313.

SANDFORD, P. A. \& CONRAD, H. E. (1966). The structure of the Aerobacter aerogenes A3(si) polysaccharide. I. A reexamination using improved procedures for methylation analysis. Biochemistry 5, I508-1517.

SPENCER, J. F. T. \& GoRIN, P. A. J. (1973). Mannose-containing polysaccharides of yeasts. Biotechnology and Bioengineering $15, \mathrm{I}-\mathrm{I} 2$.

TANAKa, H. \& PhafF, H. J. (1966). Enzymatic hydrolysis of yeast cell walls. II. Susceptibilities of isolated cell walls and ascus walls of various yeasts to the actions of bacterial endo- $\beta$-glucanases. Abhandlungen der Deutschen Akademie der Wissenschaften zu Berlin, Klasse für Medizin 6, I 13-129. 